Research Article

\title{
ASSESSMENT OF ENERGY PERFORMANCE BASED ON ENERGY AUDIT OF A HOTEL USING EXERGY APPROACH
}

\author{
Mehmet Emin Ugur OZ ${ }^{1^{*}}$, M. Ziya SOGUT ${ }^{2}$
}

This study presents an analytic assessment method of energy consumption processes that was developed to apply to the energy management systems of hotels. This method has based directly on an exergetic approach and examined energy and environmental performances using energy and exergy analysis with the pre-energy audit. The energy efficiency performance of the hotel was considered for uninsulated (Case I) and insulated (Case II) conditions. The results of the analysis show that energy consumption losses are related to not only the structural features of the buildings but also the operational management of the hotels. Also, the specific energy consumption of Case II is 43,08\% higher than the Case I. Exergetic efficiency for insulated and uninsulated conditions were found as $27.31 \%$ and $16.26 \%$, respectively. At the end of the study, some recommendations on effective energy management and the applications of a hotel were revealed.

Key words: Hotels, Energy Management, Energy Audit, Energy Analysis, Exergy Analysis.

\section{Introduction}

Increases in the energy consumption based on fossil energy resources, which is the primary reason for the environmental impact, has been motivated all sectors for investigation energy-efficient applications. According to researches of the European Union (EU), the building sector has approximately $40 \%$ of the total energy consumption and $36 \%$ of the $\mathrm{CO}_{2}$ emissions. Hotels, which are known as having high energy consumption and large complex buildings among the commercial buildings, have $6 \%$ roundly of the total energy consumption of the building sector. Hotels, as commercial enterprises, directly depends on tourism mobility and the capacity of the sector, which served 980 million people in 2011, is expected to will increase to 55\% in 2020 to serve more than 1.5 billion people [1]. A study about 610 hotels across Europe with including 40 hotels in Ankara Turkey, revealed that the amount of energy used by most hotels is between $200-400 \mathrm{kWh} / \mathrm{m}^{2}$.yr. This important potential for consumption, which is dependent on the occupancy rates of hotels, has contributed significantly to the emission production [2]. Therefore, the determination of energy efficiency and savings potential is the critical point for reducing energy waste and $\mathrm{CO}_{2}$ emissions. In the literature, many studies related energy efficiency and savings based on the building sector like commercial, highvolume buildings and hotels have found [3,4]. Energy analysis considering hotels is defined as a

\footnotetext{
${ }^{1}$ M.Emin Ugur OZ Vocational Schools of Tech. Sci., Energy Depart., Uludag Univ., Bursa, Turkey (meuguroz@uludag.edu.tr) https://orcid.org/0000-0002-2306-6008

${ }^{2}$ M.Ziya Sogut, Maritime Faculty, Piri Reis University, Tuzla/Istanbul, Turkey, (mzsogut@gmail.com) (Dhttps://orcid.org/00000002-2306-6008
} 
quantitative expression of consumption and expresses only potential use of existing energy. In this type of analysis, defining and evaluating of the system according to losses are not possible. To define irreversibility potential and energy losses of hotels are explained by exergy analyses directly. Exergy analysis in hotels is a tool to determine the real potential of energy losses and carbon footprint. [5]. Energy and exergy analyses of hotels have become prominent regarding energy management, energy costs and sustainable environments in buildings. However, few studies in the literature have focused on hotels within the scope of exergetic analyses. Gonçalves studied new energy and exergy indicators, which are suggested for legislation, regarding building energy performance in a 4-star hotel in Coimbra, Portugal [5]. Xydis et al. analyzed the energy and exergy efficiencies of four hotels in different regions of Greece using data acquired from 2001-2002 [6]. Kilkis stated that efficiency and environmental compliance could ensure lower costs for a sustainable exergy-efficient building. This situation was explained by the dynamic and controlled balance between radiant changes and convective changes in an attentive design optimization with corresponding thermal heating-cooling changes (HVAC) in the building [7].

Studies about hotels can be defined as local energy consumption analyses, per $\mathrm{m} 2$ as well and process analyses. A sustainable model about energy performance evaluation of hotels with exergy analysis has not been observed in the literature. First, this study was presented by the pre-energy audit of a hotel, which was considered under insulated and uninsulated conditions with real data. In this study, occupancy rate and per $\mathrm{m} 2$ area were considered as a reference parameter for analyses. Energy and exergy analyses for each one of two situations were calculated $\mathrm{CO}_{2}$ emissions dependent on irreversibility and energy losses. Besides, energy and emission capacity per a customer according to occupancy rate, energy saving potential according to improvement potential were found separately.

\section{Energy management and energy audit at hotels}

The global consumption of energy by hotels is approximately 360 MToe, which has an important effect on the environment due to the activities and energy-based infrastructures of hotels. Considering the hotel sector, Europe hotels have approximately a potential of $42 \%$ and 5.45 million beds capacity. According to a study made for these hotels, the average energy consumption was defined between 305 and $330 \mathrm{kWh} / \mathrm{m}^{2}$.yr with an average emissions release of $160-200 \mathrm{kgCO} / 2 \mathrm{~m}^{2}$. The energy consumed by hotels is derived mostly from fossil fuels. Natural gas and fossil fuels generate approximately $39 \%$ of the total energy for a typical hotel, whereas electricity generates approximately $61 \%$ of the total consumption for a typical hotel. When analyzing the activity structure of hotels, energy is used for heating, cooling, conditioning, lighting, and ventilation. The usage of heating requirements depends on the operations of building heating, swimming pools, and cooking [2]. According to energy savings studies that considered capacity and usage rates in hotels, maximum energy savings potentials of $30 \%$ were attained. Energy savings potentials are dependent on the place of use; in hotels in Europe, the distribution of energy use is as follows: $15-20 \%$ in heating, 5-30\% in cooling, 40-70\% in water heating and $7-40 \%$ in lighting [8].

Considering the costs of annual energy consumption of hotel, there is a need for effective and sustainable energy management. Energy management for hotels is defined as a disciplined study that is structured and organized for the efficient use of energy without sacrificing environmental conditions, service quality, comfort, and safety. This system in Turkey can be provided with an ISO 50001 Energy Management System. [9]. Effective energy management is a dynamic structure that progresses within a cycle of monitoring, planning, implementing, controlling and measuring. The primary task of energy 
management is dependent on the capability of an organization to effectively determine all energy processes and savings potentials with pre-energy searching.

\section{Exergetic approach in integrated building}

The primary objective of effective and sustainable energy methods is to maximize the energy savings potentials through the use of energy searching attached to a targeted consumption. An analysis for each energy-consuming system is important for determining the aspects required for subsequent improvments. A flow chart of the exergetic approach developed for building implementations is shown in Fig. 1.

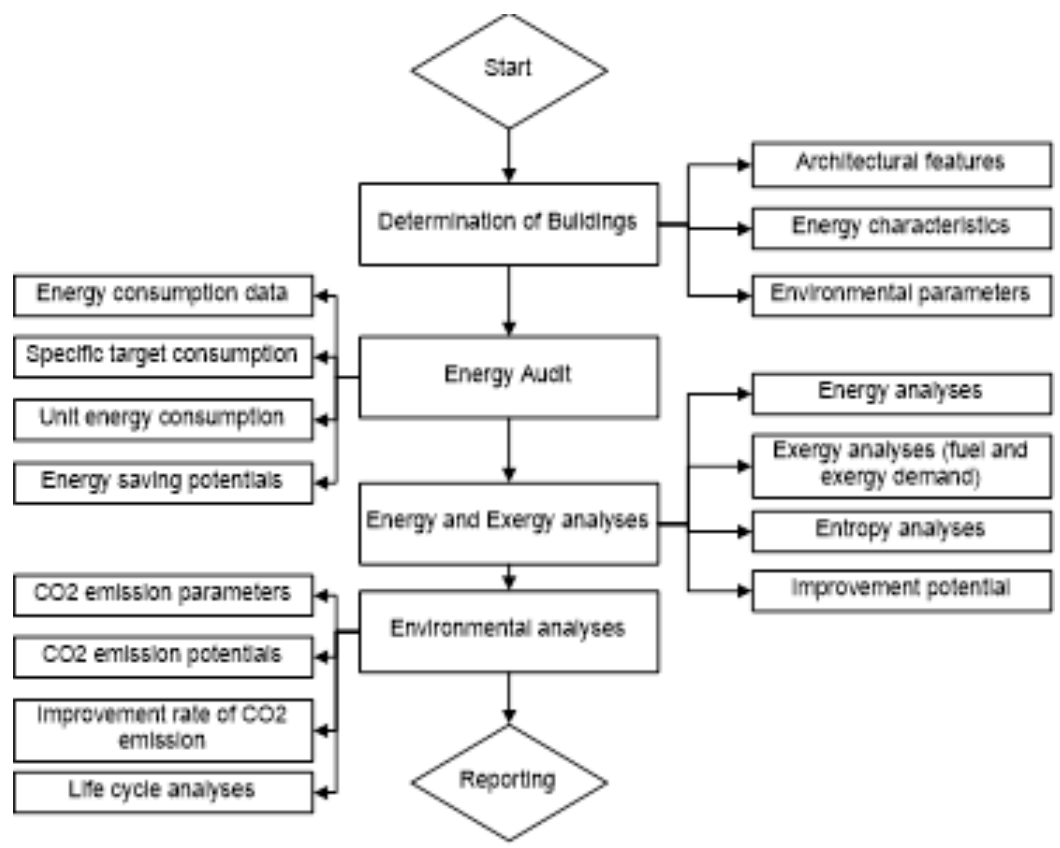

Fig. 1. Flowchart of the exergetic approach for buildings

\section{Step 1: Energy Audit}

Exergetic analysis of the process shows directly a useful performance related to irreversibility. But previously from this analysis, distribution of energy consumption of all processes should be examined and process to be studied should be determined. An energy audit is the most important stage of the methodology for developing efficiency and determining the energy savings potential. The most important stage of an energy audit is the data collection process. The data collection process requires a strategic approach to energy management. The collected data should be transformed into a standard structure, and their unit transformation should be ensured by a unit analysis. Energy management standards determine standard, target energy consumptions and energy savings potentials. The standard equation of consumption is a linear equation that demonstrates that the need for energy is dependent on specific variables. This equation is expressed as;

$$
E=a+b(P)
$$

Where the variables " $a$ " and " $b$ " are fixed, and $\mathrm{P}$ is a specific variable. After the standard equation dependent, targets are determined by considering consumption processes. The target equation is the 
same form as the standard equation. To determine the energy savings potential, the cumulative sum value (CUSUM) method is employed. This method consists of determining the total cumulative sum of the energy savings potentials from the energy data using the least squares method [10].

\section{Step 2: Exergy analysis}

Energy demands of residential or commercial buildings are generally determined as based on heat losses and gain. Energy demands in these buildings are assessed for demands, comfort conditions and thermal losses during the project process. The energy demand based on heating for a building $\left(\dot{Q}_{m}\right)$ is;

$$
\dot{Q}_{m}=\left[\dot{Q}_{h}\left(T_{\text {in }}-T_{\text {out }}\right)-\varphi_{m}\left(\emptyset_{\text {in }, m}+\emptyset_{\text {out }, m}\right)\right] \cdot t
$$

Where $\dot{Q}_{h}$ is specific heat losses of the building, $\left(T_{\text {in }}-T_{\text {out }}\right)$ is monthly the average inlet and outlet temperature, $\varphi_{m}$ is the utilization factor, $\phi_{i}$ and $\phi_{s, m}$ represents average inlet gains and average solar energy gains respectively, and ${ }^{t}$ is time[11]. Fossil fuels are generally used as the primary energy source to supply heat demands in the buildings. The amount of fuel for the total energy load $\left(\mathrm{M}_{\mathrm{f}}\right)$ is;

$$
M_{\text {fuel }}=\frac{\dot{Q}_{\text {heat }, \text { year }}}{L H V_{\text {fuel }} \cdot \eta_{\text {boiler }}}
$$

Where $L H V_{\text {fuel }}$ is the low heat value of the fuel and $\eta_{u}$ is the thermal efficiency of the boiler or heat supplier [11]. The total energy efficiency of a heating system is the ratio of annual energy demand to annual fuel consumption. According to this, the total efficiency is;

$$
\eta_{I}=\frac{\dot{Q}_{\text {heat }, \text { year }}}{M_{\text {fuel }} \text {,year. } L H V}
$$

Where $\eta_{I}$ is the total energy efficiency, $\dot{Q}_{\text {heat,year }}$ is the demand for heating energy, and $M_{\text {fuel,year }}$ is the annual fuel consumption. Considering the heat requirements of the buildings, thermal exergy is addressed accordingly heating and cooling demands related to minimum energy or fuel usage. The exergy factor firstly is the minimum exergy or heat demand depending on Carnot efficiency between inlet and output or dead state temperature. Exergy factor can also be described as the rate of energy and exergy demand for buildings. It can even be thought as a ratio of the real need in buildings to will be consumed with energy. In this case, the $\left({ }^{\gamma}\right.$ ) exergy factor is,

$$
\gamma=\frac{\dot{E}_{x}}{\dot{Q}_{h}}=\left(1-\frac{T_{0}}{T}\right)
$$

The exergy demand of a building can be considered as minimum energy demand accordingly internal comfort requirements, indoor and output temperature together with on structure components directly dead state temperature. The exergy demand is,

$$
\dot{E}_{x}=\dot{Q}_{h \cdot}\left(1-\frac{T_{0}}{T}\right)
$$

Where $\dot{Q}_{h}$ is the total heat demand of the building, $T_{0}$ is the dead state temperature or outdoor temperature, and $T$ is the ambient temperature $[9,12,13]$. The exergy load rate for buildings is dependent on the exergy load of the heating system and the exergy demand rate of the distribution system. The total system exergy of buildings depends on the heating system, the distribution system and other components that consume energy, such as DHW, HVAC or heat pump systems. The total system exergy load rate of the building becomes

$$
\dot{E} x_{\text {total }}=\dot{E} x_{H S, i n}+\dot{E} x_{d i s, i n}+\dot{E} x_{D H W, \text { in }}+\dot{E} x_{o t h e r, i n}+\sum P_{s y s, i n}
$$


Where $\dot{E} x_{H S, i n}$ is the exergy load of the heating system, $\dot{E} x_{d i s}$ is the exergy load rate of the distribution system, $\dot{E} x_{D H W, \text { in }}$ is the exergy load rate of the domestic water heater, $\dot{E} x_{\text {other, in }}$ is other component that consume energy, and $\sum P_{s y s, i n}$ is the electric power consumption of all systems. The total exergy efficiency of buildings based on the demand exergy rate:

$$
\varphi=\frac{\dot{E} x_{\text {demand }}}{\dot{E} x_{\text {total }}}
$$

Exergy is consumed in all thermal systems that are dependent on environmental conditions $[9,12,13]$. Therefore, the exergy destruction rate is an important parameter for assessing irreversibility and the entropy production of systems. The exergy destruction rate of the system can be calculated by;

$$
\dot{E} x_{\text {dest }}=\left(1-\psi_{\text {sys }}\right) \cdot \dot{E} x_{\text {total }}
$$

The rational exergy efficiency is the most accurate criteria for exergy efficiency related to building energy system[14].

The improvement of exergy efficiency for an energy process or system is based on to minimize the exergy loss or irreversibility. The exergy loss or irreversibility is based on the exergy difference between input and output of the system. The improvement potential (IP) is defined for irreversible processes of energy systems as follows $[15,16]$ :

$$
I P=\left(1-\eta_{I I}\right) \cdot\left(\dot{E} x_{\text {in }}-\dot{E} x_{\text {out }}\right)
$$

\section{Step 3: $\mathrm{CO}_{2}$ Emission Analysis}

The United Nations Environment Program can be seen at the top of these organizations, and according to the 4th evaluation report, the amount of $\mathrm{CO}_{2}$ emission was delimitated by $450 \mathrm{ppm}$. According to the pre-industrialization value $(280 \mathrm{ppm})$, this value has been expected to rise global temperature as $2{ }^{\circ} \mathrm{C}$. In recent years, scientific researches have brought to light that the target level should be limited to $350 \mathrm{ppm}$ related to boundary condition in which environmental cycles can occur, as this limit would not result in climate change [17].

$\mathrm{CO}_{2}$ emissions are considered in two aspects. The first aspect is the amount of $\mathrm{CO}_{2}$ emitted from burning fossil fuels. The second aspect is the equivalent amount of $\mathrm{CO}_{2}$. This criterion is described as a criterion for evaluating the global warming potential (GWP) and accepted as the equivalent potential of greenhouse gases like $\mathrm{CH}_{4}$ and $\mathrm{N}_{2} \mathrm{O}$, emitted by especially fossil fuel consuming systems. ( $\mathrm{GWP}_{\mathrm{N} 2 \mathrm{O}}$ :

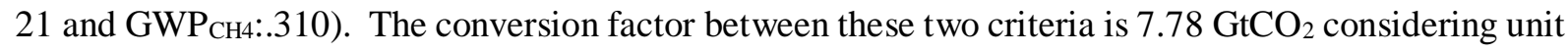
$\mathrm{ppmCO}_{2}$ [17]. $\mathrm{CO}_{2}$ emission assessment of buildings is defined considering energy consumption and relationship of the emissions and the energy is expressed by the following equation.

$$
E_{P, S E G}=100 *\left(S E G_{a} / S E G_{r}\right)
$$

Where SEG $\left(\mathrm{kg}-\mathrm{CO}_{2} / \mathrm{m}^{2}\right.$ year) states to the annual $\mathrm{CO}_{2}$ rate for per $\mathrm{m}^{2}$. "a" and " $\mathrm{r}$ " indies expresses to real and reference conditions, respectively. The emissions value of buildings is related to energy consumed and each fuel consumed has an emission factor ( F $\left._{\text {SEG }}\right)$. According to this, total emission potential is calculated as below;

$$
S E G=m_{f u e l} \cdot F_{S E G}
$$


Where $\mathrm{FSEG}_{\mathrm{SEG}}$ refers to the $\mathrm{CO}_{2}$ emission factor for each fuel like natural gas $(0.234)$ and coal $(0.433)$ $[18,19]$. The $\mathrm{CO}_{2}$ emission metrics related to the exergy concept is defined as another method in emissions analyses.

\section{Results and discussions}

In this section, the exergetic approach suggested for a hotel were applied considering a sample hotel, which has two cases including isolated and uninsulated conditions. But first, energy efficiency potential was defined based on an energy audit. Then, energy and exergy analyses of the hotel were made consequently. Structural features of the hotel were given below:

\subsection{Structural Features of Hotel}

The hotel was built in provincial borders of Bursa/Turkey, and its construction is a concrete building. Energy consumption of the hotel depends on electric and natural gas. The building's central air conditioning system is powered by steam for steam humidification. Alternatives energy systems (such as renewable) except the standard energy sources was not supported in the building. Construction components were assessed separately for building energy requirement values. The floor area of the ground contact is $2152 \mathrm{~m}^{2}$, the total area of the window is $1442.42 \mathrm{~m}^{2}$, and the total area of the doors is $13.57 \mathrm{~m}^{2}$. The total area of the wall in the project is $6693.45 \mathrm{~m} 2$, and the total terrace and roof area is $2092.97 \mathrm{~m}^{2}$. The total $\mathrm{m}^{2}$ measurement for the closed area of the hotel is $13253.04 \mathrm{~m}^{2}$. In this study, for the analytic assessment in uninsulated (Case I) and insulated (Case II) conditions were separately addressed.

\subsection{Results of the Analysis and Evaluations}

During energy audits of the hotel, the analyses for Case I and Case II conditions examined at two-way, which were defined $\mathrm{m}^{2}$ consumption and the occupancy rate. These parameters were analyzed separately considering annual consumptions.. The energy consumption distributions for both analyses are given in Table 1.

Table 1 Table 1 Energy consumption distributions of the hotel for the years of Case I and Case II

\begin{tabular}{|l|c|c|c|c|c|c|}
\hline \multicolumn{1}{|c|}{ Case } & Energy & Distribution & Unit Cost & Cost & Distribution & Unit Energy Cost \\
\hline \multicolumn{1}{|c|}{ Case I } & $(\mathrm{kWh} /$ year $)$ & $\%$ & $\$ /$ unit & $\$ /$ Total & $\%$ & $\$ /$ unit \\
\hline Electricity & 1389970.37 & 0.5599 & 0.091 & 126384.12 & 0.7609 & 0.091 \\
\hline Natural gas & 1092611.46 & 0.4401 & 0.296 & 39713.14 & 0.2391 & 0.036 \\
\hline Total & 2482581.83 & & & 166097.26 & & 0.067 \\
\hline \multicolumn{1}{|c|}{ Case II } & & & & & & 0.164 \\
\hline Electricity & 1406277.33 & 0.5969 & 0.164 & 230629.48 & 0.8505 & 0.043 \\
\hline Natural gas & 949498.50 & 0.4031 & 0.41 & 40551.05 & 0.1495 & 0.115 \\
\hline Total & 2355775.83 & & & 271180.53 & & \\
\hline
\end{tabular}


For Case I and Case II, the energy consumption for the hotel was 230.22 Toe and 211.85 Toe, respectively; the unit energy annual cost was found $0.067 \$ / \mathrm{kWh}$ for Case I and $0.115 \$ / \mathrm{kWh}$ for Case II. The energy consumption assessments for the hotels are generally performed using $\mathrm{m} 2$ as a reference. However, the occupancy rates in hotels are directly affected by the cost effectiveness. In this study, energy savings potentials were calculated using the $\mathrm{m} 2$ and the occupancy rate as references.

According to the audit results, the standard annual average $\mathrm{m} 2$ consumption for the Case I was found $16.83 \mathrm{kWh} / \mathrm{m}^{2}$, and the target consumption was defined $12.43 \mathrm{kWh} / \mathrm{m}^{2}$ with a decreasing rate of $36.6 \%$. For the Case II, the standard consumption was $14.81 \mathrm{kWh} / \mathrm{m}^{2}$, and the target consumption was $7.64 \mathrm{kWh} / \mathrm{m}^{2}$ with a rate of $48 \%$. Similar analyses were conducted using the energy consumption per capita, which is dependent on the occupancy rate of the hotel. The occupancy rates for an insulated building in Case I and Case II were found $74.64 \%$ and $51.77 \%$, respectively. Standard consumption was calculated as $1.56 \mathrm{kWh} /$ person in Case I and 1.95 in Case II. Considering capacity, the target consumptions were $1.13 \mathrm{kWh} /$ person in Case I and $1.10 \mathrm{kWh} /$ person in Case II. According to this distribution, the annual average energy savings for Case II was $59.7 \%$ for $\mathrm{m} 2$ and the savings per capita was $43.8 \%$; in Case I, the savings rates per $\mathrm{m}^{2}$ and per capita were $36.6 \%$ and $27.3 \%$, respectively

Based on the audit of a building, the cumulative total values chart (CUSUM) was only created for Case II. Based on the total consumption values for Case II, the CUSUM chart was generated using the least squares method, as shown in Fig. 2.
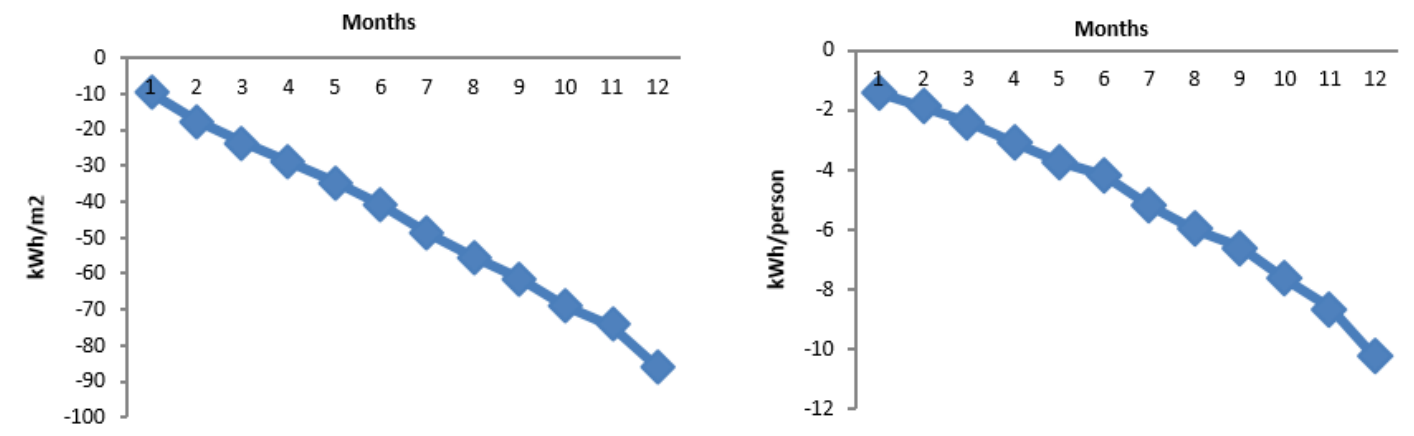

\section{Fig.2. CUSUM charts}

According to the CUSUM analyses, the savings potential was $7.16 \mathrm{kWh}$ for $\mathrm{m}^{2}$ and $48.4 \%$ and $0.86 \mathrm{kWh}$ and $43.9 \%$ per person depending on the occupancy rate. The difference was less than $10 \%$ for both potentials. The audit results, which are dependent on insulated and uninsulated conditions of the hotel, indicate a significant savings potential for the hotel. Based on these assessments, energy and exergy analyses of the hotel were made separately.

The energy sources in the hotel were natural gas and electric. The analyses were performed for the consumptions of the mechanical system by employing the consumed energy charges to satisfy the need for energy produced from the loss of heat outside of the kitchen and hot water required for laundry. The energy consumption distributions for both situations are given in Fig.3. 

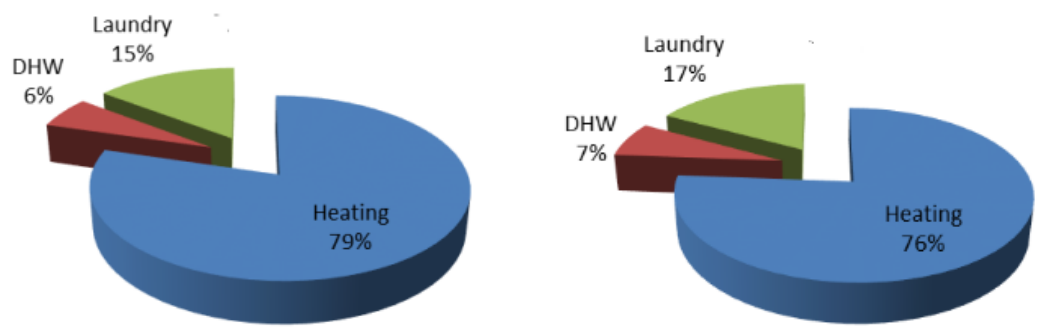

Fig.3. Energy consumption distribution for the hotel

In both usage conditions, the $\%$ variation in the energy consumption distribution is approximately $4.25 \%$. Insulation support provided savings at a rate of $43.08 \%$. When disregarding the effect of external air changes, the annual energy consumption decreased to $348203.5 \mathrm{kWh} / \mathrm{year}$ from $611323.1 \mathrm{kWh} / \mathrm{year}$. From these data, the monthly energy efficiencies of the hotel were calculated; the distributions are shown in Fig. 4.

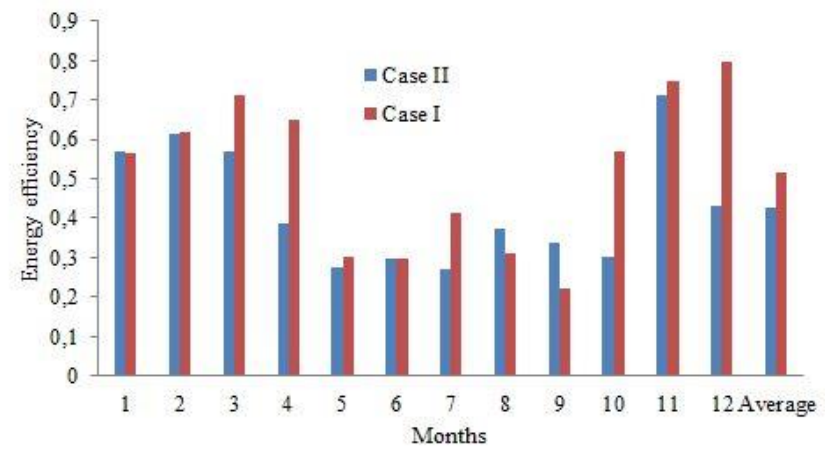

Fig.4. Energy efficiency in the hotel for Case I and Case II

In the analyses, reference values were calculated by considering the hot water demand of facilities, the individual hot water demand and loss of heat analyses. The results of the analyses indicate that the efficiency of the system is higher for uninsulated usage. The average energy efficiency was $51.72 \%$ and $42.84 \%$ in Case I and Case II, respectively. Although there is an improving effect of insulation at the rate of $43.08 \%$ in the heating requirement, other consumptions in the hotel create significant losses due to operational inefficiencies.

These results indicate that the distribution of energy consumption was directly affected by the occupancy rate of the hotel. The results of an important advantage, such as insulation, did not provide sufficient savings because a control could not be applied that was dependent on the occupancy rate of the hotel or the system did not allow this application. This distribution was also obtained with the unit hour energy consumption of energy based on the demand for natural gas. The unit energy consumption distribution for the hotel for both situations is shown in Fig. 5.

The monthly unit energy consumptions do not exhibit significant differences. An analysis of these values reveals that the annual average unit energy consumption is higher for the insulated year at a rate of $3.19 \%$. The average unit consumption for Case I was $0.779 \mathrm{kWh}$, whereas the average unit consumption for Case II was $0.804 \mathrm{kWh}$. The difference of $30.7 \%$ in the occupancy rate of the hotel is important. No system was able to control this change in the mechanical infrastructure of the hotel. 


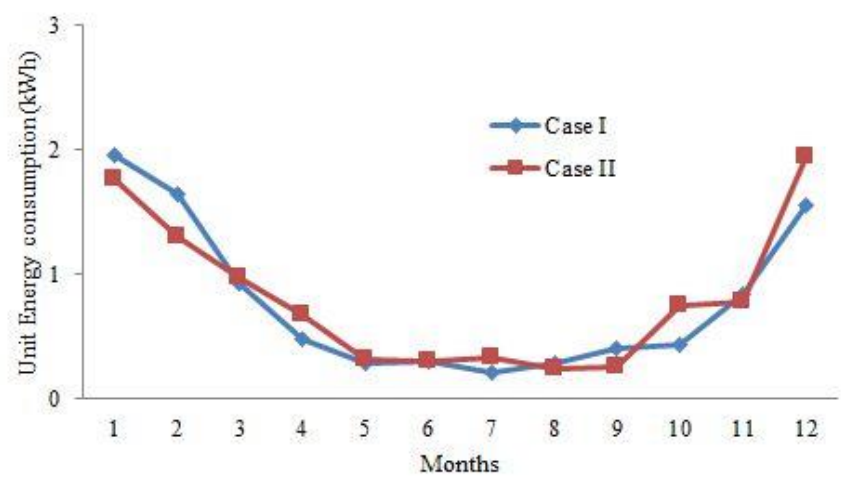

Fig.5. Energy consumption distribution for Case I and II

Concerning energy analyses of the total system distribution, the effect of consumption also yielded results that were similar to the exergy distribution. Building exergy analyses can be performed separately based on fuel and building exergy demands. If building demands cannot be directly measured in a system, the exergy analyses and efficiency of the system can be determined regarding fuel. Both approaches were analyzed in this study. The exergy consumption of the system was separately analyzed with fuel consumption as a reference, and the monthly average exergy efficiency of the hotel was calculated. The average exergy efficiency for both situations is shown in Fig. 6.

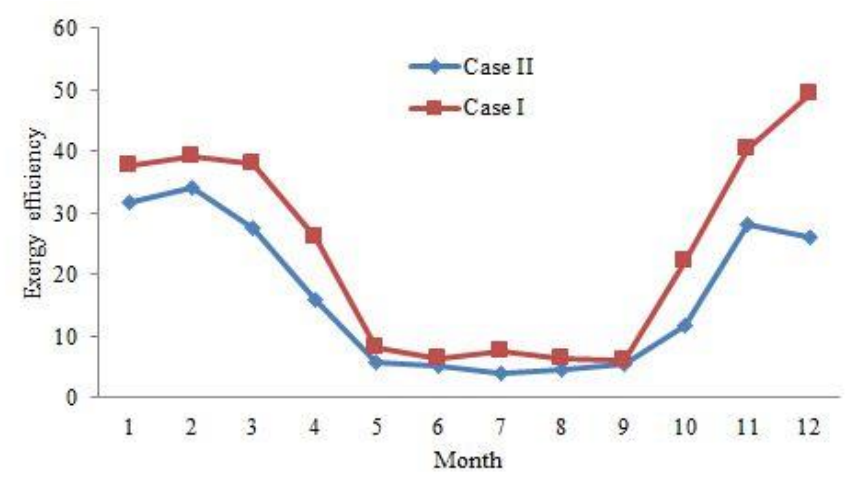

Fig.6. Exergy efficiencies of the hotel based on the fuel

As in the energy analyses, the average exergy efficiency in Case I was higher than the average exergy efficiency in Case II at a rate of $30.57 \%$. The average exergy efficiency for both years was $23.02 \%$ (Case I) and $15.97 \%$, respectively. These assessments were performed by considering the charge analyses, such as loss and gain of heat, mechanical systems, boiler and laundry, and the results were compared. In the exergy demand analyses, the efficiency was $27.31 \%$ in Case I and $16.26 \%$ in Case II. These values are close to the results obtained from the fuel exergy approach at an average error rate of $10 \%$. To display the operating charges, the results from the demand exergy approach require more detailed analyses. Thus, these charge values can be used to define the improvement potentials related to irreversibility caused by the energy consumptions of the hotel. Entropy production based on equation (14) and the related improvement potential were calculated separately. Only data for Case II were employed for future scenarios. The entropy production and improvement potential of the exergy consumption for Case II are shown in Fig. 7. 


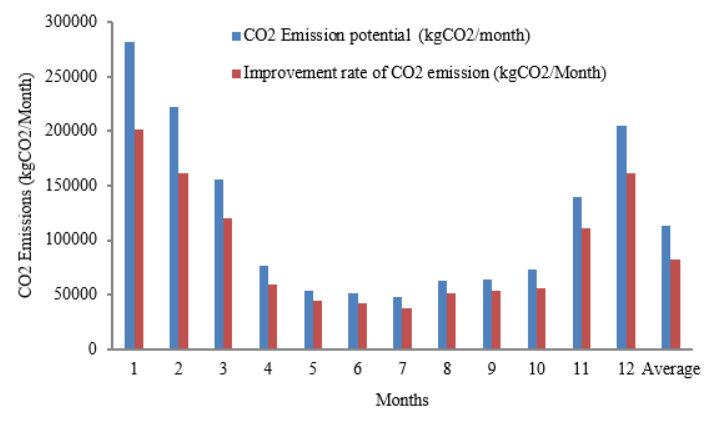

Case I

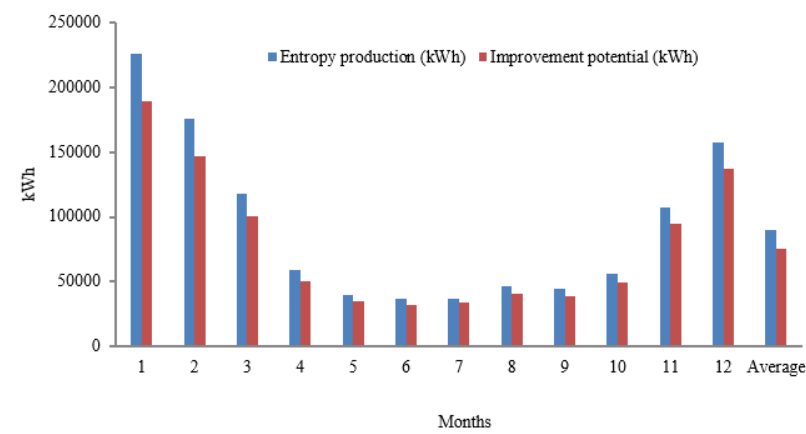

Case II

Fig.7. Entropy production and improvement potential of the hotel

In the exergy production of the hotel for the year Case II, the irreversibility for monthly average, lost exergy or entropy production amount to $89800.36 \mathrm{kWh}$. The improvement potential of this effect was $56657.29 \mathrm{kWh}$. The improvement in this potential increases the exergy efficiency of the hotel at the rate of $80.15 \%$. With adequate energy management of the hotel and effective energy usage, the improvement of this potential and emission release based on energy consumption will be positively affected.

Emission approaches in energy systems differ in many aspects. The carbon release metric was employed in this study, and $\mathrm{CO}_{2}$ emission savings based on the improvement potential with current emission release in the system were separately calculated; the results are shown in Fig. 8.

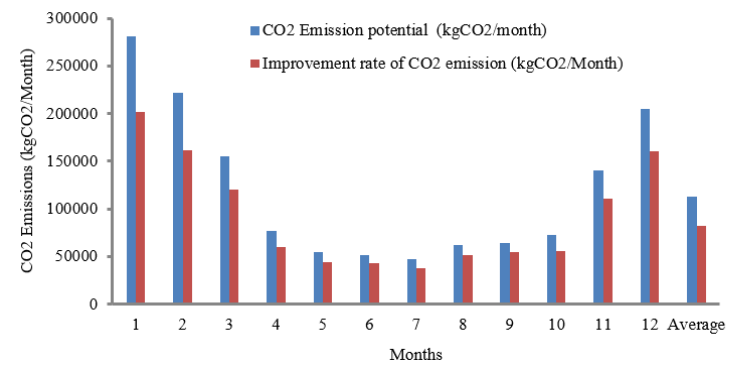

Case I

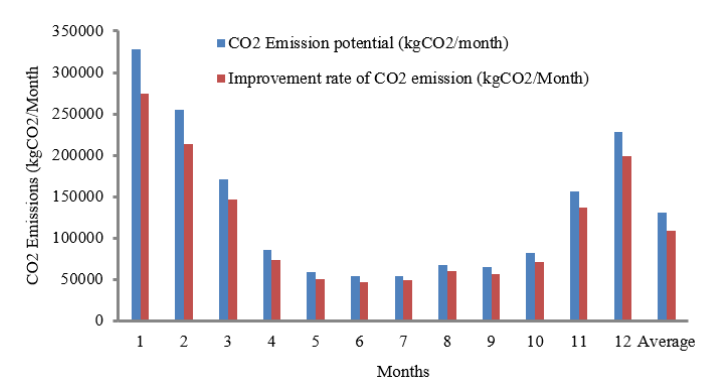

Case II

Fig.8. $\mathrm{CO}_{2}$ Emission potential and improvement rate of the hotel

Regarding energy consumption, the monthly average for the year Case I was $77946.93 \mathrm{kWh}$, and the $\mathrm{CO}_{2}$ emission potential for the hotel causing entropy production was $113.24 \mathrm{Gt}$. Considering the improvement rate, emission savings at a rate of $39.68 \%$ emerges in the monthly average of this potential. The exergy loss of the hotel based on the irreversibility in Case II was $89800.36 \mathrm{kWh}$. The improvement potential based on the exergy efficiency of the system was $83.74 \%$. The average monthly $\mathrm{CO}_{2}$ emission potential of the system was $130.46 \mathrm{Gt}_{\mathrm{CO}}$. This potential can be reduced at a rate of $23.62 \%$ via an improvement based on this potential improvement rate.

For buildings and building elements, a comparative methodology framework as namely costoptimal methodology, which is levels of minimum energy performance requirements, was published by the European Commission on 30 June 2011. 
This methodology evaluates the energy performance considering the lowest cost during the estimated economic life-cycle, cost-optimal methods have many units related to energy consumption[20,21]. In this study, the present value of energy consumption is used for cost-optimal considering target consumptions of the energy audit in insulated and uninsulated conditions. Occupancy rate and $\mathrm{m}^{2}$ parameters were taken references and results were given Fig.9.

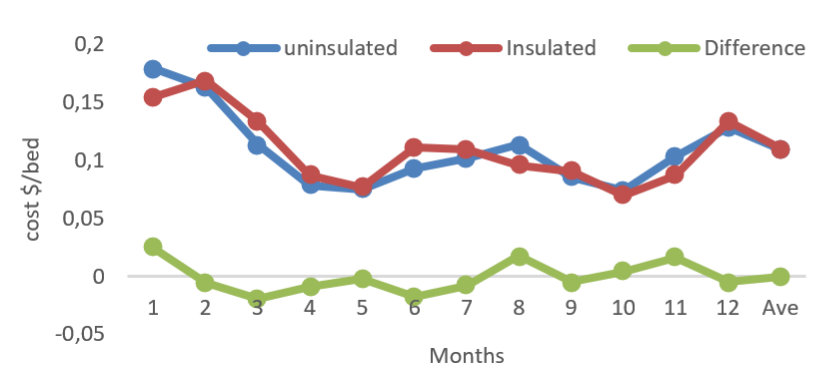

Cost based on bed

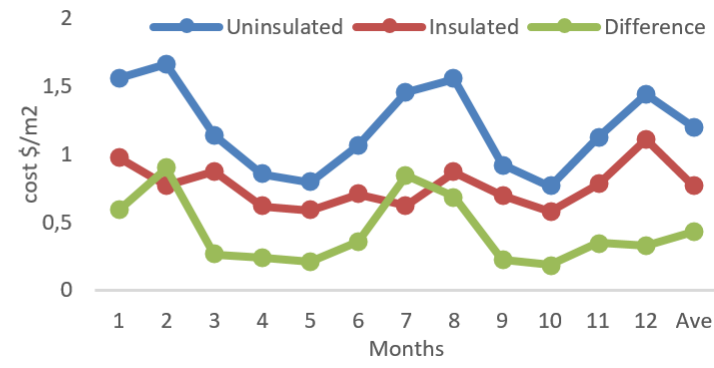

Cost based on $\mathrm{m}^{2}$

Fig.9. The global cost of the energy consumption for bed and $\mathbf{m}^{2}$

Energy consumptions in hotels must be evaluated together with climatic conditions. But the energy consumption is also an important aspect of cost-effectiveness except for the efficiency. In this context, the global cost has been found both for occupancy rate and $\mathrm{m} 2$ referred to objective consumptions by present value. According to this evaluation, energy consumption per bed for isolated and un-isolated buildings have been found respectively 0.108 \$/bed and $0.1097 \$ /$ bed. Global costs for consumptions have been found meanly $1,194 \$ / \mathrm{m}^{2}$ and $0,765 \$ / \mathrm{m}^{2}$ at the same conditions.

\section{Conclusions}

In this study, an analytic method referred to as the exergetic approach was developed as the reference for the energy management considering thermodynamic and environmental analyses The results of the study show that not only the construction specifications but also the operating structure should be evaluated as essential parameters in hotels In this context, the improvement between uninsulated and insulated conditions with a rate of $43.08 \%$ were found except for the problems in the energy management structures of the hotel. The results taken from the analysis were given as follows:

a. According to the results received from the energy audit of the hotel, the annual average energy savings of Case I was $59.7 \%$ for $\mathrm{m} 2$ and $43.8 \%$ for saving per capita. The savings rates for $\mathrm{m}^{2}$ and per capita for Case II were $36.6 \%$ and $27.3 \%$, respectively.

b. The savings potential of the hotel as a cumulative total based on occupancy rate was of $43.9 \%$ with $0.86 \mathrm{kWh}$ per capita energy consumption and $48.4 \%$ with $7.16 \mathrm{kWh}$ energy consumption for $\mathrm{m} 2$.

c. Although high-efficiency elements are used in the energy system of the hotel, the energy efficiency was $51.72 \%$ for Case I and $42.84 \%$ for Case II. The significant loss potential in the system was defined.

d. When assessing the exergy efficiency of the hotel based on fuel, the average exergy efficiency rate of $30.57 \%$ in Case I was higher than the exergy efficiency in insulated structure. The average exergy efficiency for both years was $23.02 \%$ (uninsulated structure) and $15.97 \%$, respectively. However, the 
exergy efficiency in the uninsulated structure was $27.31 \%$ and $16.26 \%$ in insulated structure, depending on the building demand and building usage.

e. The most important contribution of exergy analyses is the ability to define the improvement rate based on the loss potential. The exergetic efficiency of a hotel can be increased to $80.3 \%$ depending on the improvement rate of the hotel.

f. The improvement rate in exergetic analyses can be used as a guide to define the $\mathrm{CO}_{2}$ emission savings potential of the hotel concerning environmental effects. Thus, the $\mathrm{CO}_{2}$ emission savings rates of the hotel were $39.68 \%$ and $23.62 \%$ in uninsulated structure and insulated structure, respectively.

g. These analyses demonstrated the importance of structuring an effective energy management system for the considerable consumption of energy by hotels. The positive effects of some improvements in the system, such as insulation, did not result in financial savings for this hotel because the energy could not be effectively managed and efficiently employed. These improvement studies should be based on useful engineering studies.

Hotels have significant potential in the building and tourism sectors and have become prominent due to not only their energy consumption but also their environmental effects. This study is important because it indicates that effective energy management can be ensured with the proposed exergetic approach, mainly through conducting energy analyses. This study was performed using a method for defining the unit energy value in hotels. In this respect, this study has importance for a sustainable environment and sustainable life-cycle cost analyses.

\section{References}

[1] Karataş M., Babür S., Role of Tourism Sector in the Developing World, KMÜ Journal of Social and Economic Resarches, 15 (25): 15-24, 2013 (TR)

[2] WTO, Analysis on Energy Use by European Hotels: Online Survey and Desk Research, Hotel Energy Solutions project publications, Revised version, July 2011, Madrid, Spain,www.unwto.org.

[3] Lohani S.P. Energy and exergy analysis of fossil plant and heat pump building heating system at two different dead-state temperatures, Energy Volume 35, Issue 8, August 2010, Pages 3323-3331.

[4] Kondo, K. Energy and exergy utilization efficiencies in the Japanese residential/commercial sectors. Energy Policy 2009, 37, 3475-3483.

[5] Gonçalves P., Rodrigues Gaspar A., Gameiro da Silva M., Energy and exergy-based indicators for the energy performance assessment of a hotel building, Energy and Buildings 52 (2012) 181-188.

[6] Xydis G., Koroneos C., Polyzakis A., Energy and exergy analysis of the Greek hotel sector: An application, Energy and Buildings 41 (2009) 402-406.

[7] Kilkis B., An Exergy Aware Optimization and Control Algorithm for Sustainable Buildings, International Journal of Green Energy. 01/2004; No. 1:65-77. DOI:10.1081/GE-120027884. 
[8] Alujević V. Z., Energy Use and Environmental Impact from Hotels on the Adriatic Coast in Croatia - Current Status and Future Possibilities for HVAC Systems, Doctoral Thesis, Department of Energy Technology Division of Applied Thermodynamics and Refrigeration Royal Institute of Technology Stockholm, Sweden 2006

[9] Hepbasli A. Low exergy (LowEx) heating and cooling systems for sustainable buildings and societies, Renewable and Sustainable Energy Reviews 16 (2012) 73- 104

[10] Kedici Ö., Energy management, General Directorate of Electrical Power Resources Survey and Development Administration Energy Resources Studies Department, Ankara, Turkey, 1993

[11] Koçak S., Şaşmaz C., Atmaca İ., Examination from the technical and economic aspects of a shopping center for degree-days of different regions according to TS825 isolated, Journal of Installations Engineering Volume 128, 2012, pp. 76-88

[12] ECBCS, Annex 37 2013, Energy conservation in buildings and community systems-low exergy systems for heating and cooling of buildings, Energy Conservation in Buildings and Community Systems <http://virtual.vtt.fi/annex37/> (01.12.13).

[13] ECBCS, Annex 49, 2013, Energy conservation in buildings and community systems low exergy systems for high performance buildings and communities, Energy Conservation in Buildings and Community Systems <http://www.annex49.com> (01.12.13).

[14] Cornelissen R.L. 1997, Thermodynamics and sustainable development: The use of exergy analysis and the reduction of irreversibility, Ph.D thesis, University of Twente, The Netherlands.

[15] Van Gool W, Energy policy: fairly tales and factualities, In: Innovation and Technology-Strategies and Policies (Eds O.D.D. Soares, A. Martins da Cruz, G. Costa Pereira, I.M.R.T. Soares and A.J.P.S. Reis), Kluwer, Dordrecht, 1997;93-105.

[16] Hammond G.P, Stapleton A.J., Exergy analysis of the United Kingdom energy system. Proc Instn Mech Engrs 2001;215(2): 141-162.

[17] Algedik Ö. Role of Local Government in the Fight Against Climate Change, Civil Climate Summit Report, the Organization of Civil Climate Summit, November, 2013

[18] Bayram M. The Reference Building Concepts And Energy Classification in calculation Method of Bep-TR, X. National Installation Engineering Congress - April 13/16 /Zzmir, page 755-762, 2011

[19] Sogut M. Ziya, Hamit M., Tahir H. K., and Namık I. Investigation of effects of hydraulic balance in mechanical system based on energetic and exergetic efficiency in industrial buildings", International Journal of Exergy, 2016. 
[20] Becchio C., Ferrando D. G., Fregonara E., Milani N., Quercia C., Serra V., The cost optimal methodology for evaluating the energy retrofit of an ex-industrial building in Turin, Energy Procedia 78 ( 2015 ) 1039 - 1044.

[21] Pearce C., Harmonised Cost Optimal Methodologies for the Energy Performance in Buildings Directive, EEB Principles to Calculate Minimum Energy Performance, Requirements in Buildings, April 2010, European Environmental Bureau (aisbl); Blvd de Waterloo 34, 1000 Brussels, Belgium 